\title{
A PANDEMIA DA COVID-19 E SEU IMPACTO FRENTE À VULNERABILIDADE DO POVO BRASILEIRO
}

\author{
Tânia Suely Antonelli Marcelino Bravo ${ }^{1}$ \\ Maria de Fátima Rodrigues de Oliveira ${ }^{2}$ \\ Patrícia dos Santos Chiavelli ${ }^{3}$
}

DOI: https://doi.org/10.47306/978-65-88213-03-2.222-233

Sumário: 1 Introdução; 2 A soberania x a vulnerabilidade do povo brasileiro frente ao vírus; 3 O impacto da pandemia em relação ao gênero e a falta de informação; 4 Políticas públicas e o princípio da eficiência; 5 A fraternidade como enfrentamento mundial contra a pandemia; 6 Conclusão; Referências.

Resumo: Diante do atual cenário de pandemia devido ao COVID- 19, surge a seguinte indagação: Quais as providências e principais ações para o enfrentamento desta pandemia? O presente trabalho tem o objetivo de identificar quais os impactos da pandemia na sociedade brasileira, e quais são as principais ações governamentais para o enfrentamento da COVID-19. Através da metodologia hipotético dedutiva e a análise de sites da internet, conclui-se que a população brasileira está vulnerável frente a esta problemática, e faz-se necessário a garantia e efetivação dos direitos fundamentais à luz da Constituição da República Federativa do Brasil, de 1988, sendo o princípio da eficiência e o da fraternidade essenciais para o enfrentamento da pandemia.

Palavras-chave: Direitos Humanos; Soberania; Fraternidade; Pandemia.

\section{Introdução}

A COVID-19, conhecido como o Novo Coronavírus, tornou-se uma pandemia e tem causado grandes impactos no mundo como qualquer catástrofe causa. Diante dessa problemática identifica-se uma nova concepção de soberania estatal que futuramente poderá acarretar problemas maiores em relação a sociedade internacional frente a ONU, Organização das Nações Unidas e a OMS, Organização Mundial da Saúde, organizações que estão atuando

\footnotetext{
1 Doutorado em Sociologia pela USP. Pós-Doutorado em Educação pela Universidade do Minho e pela Universidade de Valência. Docente do Departamento de Administração e Supervisão Escolar e do Programa de Pós-Graduação em Educação da UNESP-Marília. E-mail: tamb@terra.com.br

${ }^{2}$ Graduanda do décimo termo de Direito pela UNIVEM- Universidade Eurípides de Marília, membro da Comissão de Pesquisa do NAPEX, participante do Núcleo de direitos humanos e cidadania-NUDHUC, do grupo de pesquisa NUDISE, Núcleo de Diversidade Sexual na Educação. E-mail: m.fatimaro@hotmail.com

3 Graduanda do décimo termo de Direito pelo UNIVEM- Universidade Eurípides de Marília. E-mailpatriciachiavelli@gmail.com
} 
ativamente no combate a pandemia de fundamental para desenvolver medidas em prol da saúde global e na garantia dos direitos humanos.

Em síntese, é necessário destacar que a soberania influi diretamente nas atitudes das nações por estar ligada a uma concepção política de poder, de organização jurídica e de fazer valer dentro do seu território a universalidade de suas decisões nos limites de fins éticos de convivência, conforme o pensamento de Jean Bodin (1992), assim a soberania é facilmente compreendida dentro das qualidades de um Estado.

A soberania de um Estado está na garantia de assegurar a população seus direitos mais básicos e fundamentais, como é o caso da dignidade humana, da informação transparente de suas ações, como de atendimento à saúde básica, condições de trabalho digno, visando efetivar os direitos humanos que são tão inerentes, frente a vulnerabilidade do povo brasileiro.

O mundo já passou por outras pandemias e no fim se restabeleceu com grandes ganhos e força, graças a solidariedade entre os povos. No Brasil não será diferente, a pandemia poderá ser como um despertar a democracia, se todos se atentarem na necessidade do enfrentamento fraterno entre os povos. As mudanças que estão já surgindo no campo da economia, por exemplo, há de se intensificar diante de novas alternativas, baseadas na soberania do Estado para com seus povos, para isso é necessário um plano de ação estratégico no combate a Covid19, responsabilidade do governo brasileiro diante da devida conjuntura.

O Brasil sofre por passar por esta pandemia num momento político caótico, de desiquilíbrio entre os poderes, desinformação devido às "fake news", violação dos direitos humanos. Apesar de todo o esforço da OMS, da ONU e de outras organizações governamentais e não governamentais, o povo brasileiro corre o risco de uma desmocratização capitalista e autoritária, por isso a necessidade da informação como direito fundante do Estado Democrático de Direito, o que é essencial neste momento de crise.

O confinamento social é a melhor forma de lutar contra este vírus que continua matando as pessoas, principalmente aquelas mais vulneráveis, como veremos ao longo do texto. Dados significativos mostram essa letalidade principalmente entre as mulheres, negros, idosos e pobres, portanto, há necessidade de um plano para suprir essas carências no que diz respeito a esses grupos.

Por fim, conclui-se que sem a união fraterna dos povos, das soberanias, não conseguiremos êxito contra esta doença. 


\section{A soberania $x$ a vulnerabilidade do povo brasileiro frente ao vírus}

A soberania internacional é considerada um direito fundamental entre os Estados, ainda que a autonomia se faz presente em cada um deles de forma marcante e primordial, assim a humanidade é o elemento que ocupa um lugar neste Estado num contexto mundial, com garantias jurisdicionais internacionais ao lado dos nacionais.

Para Bodin, (1992) a teoria da soberania está ligada a uma concepção política de poder, de organizar-se juridicamente e de fazer valer dentro de seu território a universalidade de suas decisões nos limites dos fins éticos de convivência, ou seja, a soberania é compreendida como uma qualidade essencial do Estado, tendo como características um poder superior, incondicionado. Contudo, no contexto externo ao território do Estado, ou seja, no Sistema Internacional, deu-se origem a novos estudos sob o ponto de vista das relações internacionais na qual a soberania passou por uma nova concepção onde é necessário voltar o olhar a coletividade, visando o bem de todos. E é neste sentido que a pesquisa trata, do olhar fraterno que a pandemia desperta.

Conforme o entendimento de Grócio, op: (Lafer, 1995) a sociedade internacional tem um potencial de sociabilidade e solidariedade, da qual a soberania está ligada aos interesses comuns. A convivência internacional transcende o subjetivismo da soberania e de seus interesses particulares, o que traduz a razão abrangente da humanidade e do indivíduo como fim e não como meio. Kant, op: Lafer, (1995) considerando os termos globais, afirma que vão além dos interesses das soberanias e sim de toda a sociedade internacional.

A pandemia do novo Coronavírus vai além de uma crise sanitária. Ela evidencia a severa crise política, econômica e socioambiental, marcada pela violência, negação dos direitos básicos, do espaço de atuação da sociedade civil, avanço do autoritarismo, ações genocidas e recrudescimento das estratégias anti direitos, que aprofunda os ataques à democracia brasileira pelas forças fascistas, milicianas, autoritárias, militaristas e capitalistas pelo poder patriarcal, racista e etnocêntrico, pela LGBTfobia.

O governo deve se preocupar com a soberania na sua autoridade estatal, porém sem esquecer dos deveres para com sua nação, informando e cuidando do povo, por exemplo: a OMS, tem adotado medidas essenciais para o combate ao vírus, elaborando padrões internacionais na área de saúde pública e estimulando a cooperação internacional entre as nações, a fim de garantir os direitos humanos. Uma das características fundamentais dessa organização, é o caráter técnico científico, onde as delegações na Assembleia Mundial de 
Saúde, devem ser escolhidas entre as personagens mais qualificadas e pela competência técnica no domínio da preservação da saúde.

Dessa feita, é sabido que o atual cenário mundial no combate à Covid-19 como parte dessa relação internacional, na qual se busca a solução em âmbito internacional e os interesses comuns de toda sociedade mundial, com o objetivo de garantir os direitos humanos e estabelecendo a colaboração entre os países por meio de instituições como a OMS.

O mundo já sobreviveu a outras pandemias, como foi o caso da Gripe Espanhola em 1918, onde morreu mais de um quarto da população. A crise no sistema de saúde, uma pandemia gera várias mudanças em diversos fatores, como é o caso da economia, por vivermos na era do capitalismo selvagem. Na atualidade muitos países dão mais importância para a economia ao invés das pessoas, em um país como o Brasil onde a diversidade não tem valor, o desiquilíbrio de classes é alarmante e onde o preconceito impera, fica muito pior o quadro da pandemia, há muitas pessoas que não têm casa e nem água para beber e para lavar as mãos. Como pode-se refletir, conforme:

A crise e COVID-19 parte da certeza de que a Calamidade Pública que estamos
vivendo demanda respostas velozes. Todavia, a agilidade do processo não pode servir
de justificativa para a adoção de medidas e procedimentos autoritários e obscuros, que
podem levar à morte milhares de brasileiras e brasileiros. Tampouco pode ser
subterfúgio para, valendo-se do ritmo mais célere da tramitação de propostas
legislativas neste período de crise, violar e restringir direitos, suprimindo direitos de
trabalhadoras e trabalhadores, enquanto adota privilégios fiscais a empresas e bancos.
(Observatório de Direitos Humanos, 2020, p. 4).

Destaca-se que mesmo nas grandes Nações a falta de informação é crucial, sem contar com a discriminação de negros, indígenas e pobres, neste sentido o Coronavírus é seletivo também. Atinge mais pessoas idosas, já com doenças pré-estabelecidas, isso lá fora, porque aqui a população mais atingida são as pessoas pretas e pardas que são acometidas com doenças como a hipertensão arterial, diabetes, anemia falciforme, dentre outras. E a população indígena que é mais vulnerável às doenças do homem branco desde a colonização, como mostra a Carta de manifesto, do Observatório de direitos humanos- Covid-19, Artigo 19. (2020, p.2).

A alarmante subnotificação de casos, dificuldades e negação de acesso a tratamento e exames ampliam os problemas enfrentados por povos e comunidades tradicionais, indígenas e quilombolas no combate à doença. Some-se a isso a continuidade da violência, garimpo ilegal, desmatamento e invasão dos seus territórios, resultando em um verdadeiro etnocídio, bem como, grilagem de terras públicas a e destruição da floresta amazônica.

O racismo institucional no acesso a recursos, direitos e serviços, em especial a tratamento e cuidados de saúde, desvela uma letalidade implacável da doença sobre a população negra. A invisibilidade e falta de resposta das instituições responsáveis sobre a gravidade do alastramento da doença entre a população prisional aponta para uma tragédia silenciada no sistema carcerário. 


\section{0 impacto da pandemia na questão de gênero e a falta de informação}

A pandemia como qualquer outra tragédia provoca uma comoção mundial e é impossível analisar os impactos sem as informações corretas, sendo o direito à informação, um direito fundamental. Com as novas tecnologias, as informações chegam rapidamente, no entanto elas podem vir totalmente equivocadas, é necessário haver transparência e responsabilidade no que diz respeito à saúde e à vida para todos.

Os acontecimentos meteorológicos extremos (Tsuname, ciclones, inundações, secas, subida do nível do mar decorrentes do desgelo dos glaciares), além das agressões ao meio ambiente, terá como consequência maiores ocorrências de epidemias e pandemias que surgirão cada vez mais globais e letais. A História mostra que após essas tragédias a humanidade se põe firme de novo, graças à força e à coragem das mulheres. (SANTOS, 2020 p. 31).

Conforme Boaventura de Sousa Santos destaca acima, elas são as cuidadoras do mundo, a elas foi designado este importante papel, de restaurar, restabelecer e, portanto, sofrem duplamente as consequências da pandemia, sem contar com o isolamento, e os cuidados de higiene que elas têm de proporcionar a toda família, enquanto os homens ficam ocupados em seus egocentrismos machistas, como nos períodos pós-guerra. A medida do confinamento social não está sendo bem aceita pela sociedade em geral, claramente o ser humano é um ser social, assim sendo este provoca stress e até um certo grau de angustia e depressão. De repente, a liberdade nos é tolhida por conta de um inimigo invisível e poderoso, o que provoca rumores e descrença nas pessoas.

O isolamento é uma estratégia sugerida pela Organização Mundial da Saúde a exemplo dos outros países que adotaram a medida com resultados favoráveis, mas será tão difícil entender tal proposta? Neste sentido é que ressaltamos a importância da pesquisa, com dados e estatísticas, nas quais o governo deve se apoiar para obter os resultados que os outros países obtiveram.

No Brasil o isolamento foi proposto apenas porque não tinham condições de manter o sistema de saúde ativo e adequado, para proporcionar atendimento para as vítimas da Covid19. Fatos como este que no futuro pode levar a distinguir não só entre o Estado Democrático e o Estado de Exceção, mas também entre o Estado de Exceção democrático e o Estado de exceção antidemocrático, o que significa um retrocesso. Esse isolamento pode provocar as mais variadas reações, uma delas que tem ocorrido com relação ao homem que passa a ingerir mais bebidas alcoólicas, e outras drogas psicoativas, causando o aumento da violência doméstica ou, no caso das famílias onde já existia a violência, neste momento tem sido agravada. 
A mulher sempre sofreu a dominação do patriarcado e até hoje quando o feminismo está avançando pelos países da América Latina, a violência doméstica, a discriminação sexista e o feminicídio só aumentam. O isolamento é um ato discriminatório, à medida que não é para todos, como por exemplo as profissionais da saúde que na maioria são mulheres. Elas são obrigadas a sair das suas casas para cuidar dos outros, na linha de frente se arriscando a contaminar-se e contaminar os membros da sua família. Esses (as) profissionais necessitam de equipamentos adequados, como máscaras, luvas, aventais de proteção, que já estão em escassez, quando não pecam pela qualidade ou quantidade, o que faz desse grupo de profissionais serem vulneráveis também.

A informação é muito importante no que diz respeito aos cuidados de higiene, uso correto das máscaras, são medidas educativas para o enfrentamento da doença. Este monitoramento do isolamento social deve ser constantemente avaliado, pois se forem suspensos antes do momento adequado, ou seja, antes da pandemia deixar de ser autossustentada, teremos que voltar para enfrentar uma nova onda, com crescimento dos casos de infecção. Durante este impacto ocorreu, também, a suspensão temporária das aulas presenciais do calendário escolar, de todas as áreas do conhecimento inclusive do curso de Medicina, assim como dos vestibulares. Conforme se constata, no Brasil, há falta de informação, falta de efetivação nos dados de óbito, devido à carência de testes e, assim, o número verídico de óbitos causados pelo Coronavírus é mascarado em boa parte do país.

A omissão de casos e a gravidade dos riscos da pandemia é uma evidente violação dos direitos fundamentais contemplados na Constituição federal, o que viola também as normativas internacionais como da Convenção Americana de Direitos Humanos e da Organização dos Estados Americanos, embora o Brasil seja signatário de tais normativas.

Há um grande desafio pela frente para os hospitais em reorganizar o atendimento, ampliar leitos de UTI, assim como realizar testes suficientes para o diagnóstico. O problema é que muitos desses (as) profissionais estão adoecendo e sendo afastados ou morrendo, o que pode levar o sistema de saúde a um colapso da assistência hospitalar, como ocorreu na Itália e na Espanha. No Brasil, o Ministério da Saúde aponta 169 profissionais da saúde que morreram com a Covid-19, desses 42 (25\%) foram enfermeiros, 18 (11\%) médicos e outros 88 dos 169 mortos não foram informados. Dados de 12/06/2020.

Outro fator importante é o formato das pesquisas revelando as informações corretas de onde encontrar os medicamentos eficazes e até a tão almejada vacina que muito provavelmente só estará disponível em 2021, no pós- pandemia. (MEDEIROS, 2020). 
Judith Butler (2020), ressalta que a desigualdade econômica e social também é uma forma de violência, para ela a pandemia gera uma crítica contra o capitalismo. Afirma, ainda, que a solidariedade, tem sido intensificada e será mais ainda após a descoberta da vacina. Entretanto, pode ocorrer que esta Nação ao fazer a descoberta e começar a produzir a vacina poderá valer-se de vantagens para seu país, dependendo das autoridades em disputa por este poder. No momento este vírus traz à tona as desigualdades estruturais, ele atinge mais fortemente as pessoas idosas, a população pobre e as mulheres. Quando esta mulher é negra e profissional da saúde ou mãe solo que precisa sustentar sua família, a situação se agrava na interseccionalidade, conforme já apontava Heleieth Saffioti (2015) e outras autoras feministas, desde a década de 1970. Não há como estudar gênero sem considerar a questão de classe e raça/etnia. Neste período da pandemia, ficam evidentes as desigualdades, que são agravadas.

Pensar na vida humana digna, como garantia da Constituição brasileira, e que é dever do Estado, não há de se escolher qual dessas vidas é mais importante. Por fim, Butler (2020) defende que se deve ultrapassar a ideologia do individualismo para alcançar a paz e a fraternidade, há de se desenvolver o ativismo cooperativo. É preciso se colocar no lugar do outro e da outra, contribuindo para a concretização da cultura dos Direitos Humanos

Os países da América Latina, designada por Boaventura de Sousa Santos (2020) não é um espaço geográfico e sim um espaço tempo político, social e cultural onde os seres humanos sofrem discriminação racial, sexual e a exploração capitalista. Em se tratando das mulheres, conforme já ressaltamos, a situação piora no caso do isolamento, o trabalho doméstico aumenta, os homens ficam estressados por não poderem sair de casa e acabam descontando nas mulheres, não ajudam nos afazeres do lar em face do machismo que impera, reforça a crise conjugal e familiar. Neste sentido há que se levar em conta a interseccionalidade quanto ao lugar, ao gênero, raça/etnia e toda a situação do momento.

Outro problema agravado é o das crianças pobres que iam para a escola principalmente para receber a merenda. Agora, confinados dentro das casas, ficam entediadas o que dificulta ainda mais o trabalho da mãe. Segundo os dados do Ligue 180 disponibilizados, houve um aumento de $17 \%$ de denúncias de violência doméstica só no mês de março no Rio de janeiro, um aumento de 50\% após o isolamento e distanciamento social. Acompanhando este cenário também se nota aumento do caso de violência contra crianças e adolescentes, considerando também as restrições de movimentos, limitações financeiras, inseguranças que reforçam o poder dos abusadores.

A busca por proteção também fica prejudicada com a interrupção de serviços da comunidade, creches, escolas o que faz a mulher mais vulnerável à violência psicológica e 
coerção sexual. Na Espanha, por exemplo, as mulheres podiam ir à farmácia e denunciar se estivessem sofrendo violência.

Estes problemas trazem à tona questões estruturais em relação a desigualdade de gênero. Dentro de suas casas muitas mulheres sentem medo, por já viverem situações de violência e, no caso de crianças e adolescentes, sentem a angustia de estarem longe dos (as) colegas. Diante desse quadro, a ONU Mulher elaborou um documento sobre o impacto e implicações da pandemia e as diferenças entre os gêneros, onde reforça que no contexto de emergência houve um aumento de violência dentro das casas.

Relatórios da ONU-Mulher mostram o aumento de violência doméstica que recebeu os dados do Ministério da Justiça um saldo de 17\% nos casos de violência de gênero, especialmente nas áreas urbanas, em 26/06/20 afetava uma a cada 3 mulheres em todo o mundo.

Instituições governamentais e não governamentais estão tendo iniciativas nesse cenário, divulgando formas de proteção, por exemplo: o atendimento $24 \mathrm{~h}$ do ligue 180 , disque 100, polícia civil, a manutenção do trabalho de conselheiros tutelares por plantão.

\section{Políticas públicas e o princípio da eficiência}

Diante do contexto sobre enfrentamento da pandemia, no que diz respeito à saúde, um dos princípios essenciais para a sua efetivação é o princípio da eficiência. Nesse sentido, faz-se necessária a compreensão de políticas públicas no sentido de que se está relacionada ao princípio da eficiência.

Para Bucci (2006) a política pública é definida como um programa de ação governamental, porque consiste num conjunto de medidas articuladas (coordenadas), cujo escopo é dar impulso, isto é movimentar a máquina do governo, no sentido de realizar algum objetivo de ordem pública ou, ótica dos juristas, concretizar um direito.

Em se tratando de pandemia, as políticas públicas são fundamentais para o enfrentamento e combate a COVID-19. Entretanto, as políticas públicas vêm sendo deflagradas quando não são ineficazes desde a implementação da Emenda Constitucional n. 95, de 2016, segundo a qual foram feitos vários cortes orçamentais essenciais tornando o cidadão e a cidadã mais vulneráveis ainda, como demonstrado nos dados do relatório da INESCO:

O Brasil com baixa imunidade, (INESC, 2020), (Instituto de Engenharia de Sistemas e Computadores):

De 2014 até 2019 a queda de orçamento nas áreas sociais chegou a 8,6\%;

$\mathrm{Na}$ área da saúde, deixaram de ser investidos R $\$ 30$ bilhões nos últimos anos. Dados do Cadastro Nacional de Estabelecimentos de Saúde, apontam que, entre 2007 e 2019, 
houve redução de oferta de 49 mil leitos de UTI, no país, o que afeta diretamente as estratégias de enfrentamento do Covid-19.

$\mathrm{Na}$ educação foram perdidos R $\$ 7$ bilhões.

O orçamento da assistência social caiu $9,2 \%$,

A execução financeira das políticas para as mulheres vem caindo sistematicamente desde 2014, uma queda real de $75 \%$ entre 2014 e 2019 ,

Os recursos para a saúde indígena no âmbito do Ministério da Saúde estão minguando, alcançando R\$ 1,5 bilhão em2019, menor valor dos últimos anos,

O mesmo acontece com o programa de promoção da igualdade racial, cujos recursos gastos no mesmo período diminuíram em $81 \%$,

O orçamento empenhado em 2019 para a política quilombola, em especial a titulação das áreas essencial para a permanência na comunidade, foi o menor em toda a história recente da política.

Desta feita, tem-se que as políticas públicas neste cenário de pandemia são essenciais para a efetivação do princípio da eficiência da saúde pública.

Nesse sentido, a título de exemplo, nota-se uma pequena sensibilização por parte do governo brasileiro perante a pandemia da Covid-19 com a aprovação da Medida Provisória 921, de 2020, que liberou a quantia de R\$ 1.128 milhões ao Ministério da Defesa em caráter de urgência para que as políticas públicas passassem a cobrir as despesas e atender os mais necessitados, porém verifica-se ainda uma certa debilidade no planejamento de distribuição dessas verbas, sendo que muitas pessoas ainda não gozaram de tal direito.

\section{A fraternidade como enfrentamento mundial contra a pandemia}

Voltando ao modelo clássico de Kant, na convivência internacional que traz o subjetivismo das soberanias e de seus interesses tendo como fim o ser humano e não o meio, o Estado democrático é para o governo que é para o indivíduo e não o contrário. Nesse sentido, o Governo tem o dever de ser solidário e não fazer valer sua soberania como meio. Ademais, todas as nações devem se apoiar numa situação de calamidade para que juntos possam enfrentar a experiência de reconstruir a sociedade, aplicando o princípio da fraternidade.

Toda dificuldade que emana no fim de uma catástrofe traz o direito da autodeterminação e um processo de descolonização, ao passo da soberania voltada à humanidade e à solidariedade.

[...] um mundo caracterizado por polaridades definidas não impediu para fazer algumas referências necessárias ainda que esquemáticas, o esforço internacional voltado para prevenção e a repressão do crime do genocídio, para eliminação da discriminação racial, para a supressão do apartheid, para a abolição da discriminação das mulheres. (LAFER, 1994).

Essa situação de seletividade política de interesses voltados aos Direitos Humanos dos quais podemos destacar os valores da liberdade, da igualdade e da fraternidade, na acepção de solidariedade, conforme o próprio prefácio da nossa Constituição federal, de 1988, que afirma 
os Direitos Humanos e contempla uma sociedade fraterna, pluralista e sem preconceitos. Aqui a fraternidade evoca a todos os brasileiros e brasileiras o dever de serem fraternos uns para com os outros, partindo da Tutela estatal que, no caso do Brasil, ainda não se tem. Neste sentido, não temos ainda um plano de contenção da pandemia apesar de ter mais de 36 mil mortos e mais de 691 mil infectados pelo vírus. O número verídico de óbitos causados pelo Coronavírus é mascarado em boa parte do país, o que demonstra a falta de fraternidade por parte das autoridades, não realizando o que é dever delas.

Ao pensar em direito da fraternidade, se pensa logo na dignidade humana, ambos princípios estão interligados pela própria condição humana que nos é inerente, assim como na fragilidade do ser humano que representa apenas $0,01 \%$ dos seres vivos do planeta Terra. (SANTOS, 2020, p. 23).

\section{Conclusão}

Conclui-se que existem diversos impactos na sociedade brasileira ao enfrentamento da pandemia e que é necessário unir esforços e um planejamento governamental para a efetivação dos direitos fundamentais.

Neste diapasão além das medidas e providências adotadas, verifica-se que as políticas públicas são essenciais para a concretização do princípio da eficiência e de modo a garantir a saúde pública. Destaca-se que o papel dos governantes é garantir o cumprimento dos direitos da população, pois é obrigação do Estado assegurar e promover os direitos humanos, econômicos, sociais, culturais e ambientais através da elaboração e implementação de leis e políticas públicas.

Destarte, a fraternidade é outro aspecto fundamental ao enfrentamento da pandemia, justificando-se para tanto a garantia dos direitos humanos, visando a garantia da ordem jurídica pautada na política de interesses para a efetivação dos valores da liberdade, da igualdade e da fraternidade, na acepção de solidariedade.

O controle da pandemia deve ser pautado pelos direitos de todos, à saúde e a proteção social pelo dever do estado de garanti-los por meio do fortalecimento do Sistema Único de Saúde (SUS) e do Sistema Único de Assistência Social (SUAS) que são essenciais.

Essas ações devem ser articuladas com medidas que garantam a dignidade dos (as) trabalhadores (as) em diversas situações laborais, desde a informalidade, bem como a valorização do trabalho doméstico e de sua proteção social, não esquecendo também os (as) 
trabalhadores (as) do sexo, a população que vive em locais de rua, pessoas encarceradas, os (as) idosos (as), os indígenas e outros segmentos vulneráveis.

\section{REFERÊNCIAS}

BODIN, Jean. Los seis libros de la República, $2^{\mathrm{a}}$ ed. trad. Pedro Brava Gala: Madrid: Tecnos, 1992.

BUCCI, Maria Paula Dalari. O conceito de política pública em direito. São Paulo: Saraiva, 2006.

BUTLER, Judith, In: Entrevista à Ver. Marie Claire, Feminismo e a pandemia do Coronavírus, Ed. Junho, 2020.

BRASIL. Constituição da República Federativa do Brasil. Promulgada em 05 de outubro de 1988. Organização do texto de Juarez de Oliveira. Série Legislação Brasileira. São Paulo: Saraiva, 2018.

BRASIL. https://artigo19.org/blog/2020/04/29/observatorio-de-direitos-humanos-e-covid-19direitos-humanos-como-via-para-superacao-da-crise-e-pandemia/> Acesso em junho, 2020.

HEALTH TECH, Funcional- https://www.revelo.com.br/empresas/funcional-healthmanagement. Acesso, em maio de 2020.

INESC. TEC- https://www.inesc.org.br< acesso in: maio, 2020>.

LAFER, Celso. A reconstrução dos direitos humanos. São Paulo: Cia. Das Letras, 1988.

LAFER, Celso. A soberania e os direitos humanos- Painel apresentado na XV Conferência Nacional da OAB, 1994.

LAFER, Celso. A soberania e os direitos humanos. In: Lua Nova: revista de Cultura e Política, $\mathrm{n}^{\circ} .35$, São Paulo, 1995. Op: KANT, Immanuel, GROCIO, Hugo $<$ http://www.scielo.br/scielo.php?pid=S0102-64451995000100006\&script=sci_arttext $>$ Acessado em maio de 2020.

MEDEIROS, Eduardo Alexandrino Servolo covid-19 em desafios para o enfrentamento da pandemia hospitais universitários, Revista Paulista de pediatria. Vol. 38. São Paulo 2020. Abril-2020.

MINISTÉRIO DA SAÚDE < Coronavírus.saúde.gov.br $>$ Acesso em junho, 2020.

SAFFIOTI, Heleieth. Gênero, patriarcado e violência. São Paulo: Expressão Popular/ Fundação Perseu Abramo, 2015.

SANTOS, Boaventura de Sousa. A cruel pedagogia do vírus. Ed. Almedina, Coimbra, 2020. 
$<$ https:/www.nacoesunidas.org/chefe-da-onu-alerta-para-aumento-da-violencia-domesticaem-meio-a-pandemia-do-coronavirus/> Acesso em Junho, 2020.

$<$ https://drive.google.com/file/d/1-

xEFsbeDt1xBCqG9NKonaY23GsuppmU9/view?fbclid=IwAR3477BTgJcbZxhP4VV3ZzjEj

R6nVCyWdcgsyilJlnxO29VtwF4fYCKiGy0>Carta de manifesto do Observatório de

Direitos Humanos- Covid-19. Acesso em: junho, 2020. 